\title{
Effect of saline infusion for the maintenance of blood volume on pulmonary gas exchange during temporary abdominal aortic occlusion
}

\author{
F.F. Amorim, \\ B.V.P. Pinheiro, O.S. Beppu \\ and $\mathrm{H}$. Romaldini
}

\author{
Disciplina de Pneumologia, Departamento de Medicina, \\ Escola Paulista de Medicina, Universidade Federal de São Paulo, \\ São Paulo, SP, Brasil
}

\begin{abstract}
Correspondence

F.F. Amorim

SHIS, QI. 15

Conjunto 03, Casa 10

71635-230 Brasília, DF

Brasil

E-mail: ffamorim@gmail.com

Publication supported by FAPESP.

......................

Received March 29, 2006 Accepted December 21, 2006

Accepted December 21, 2006

We analyzed the effects of saline infusion for the maintenance of blood volume on pulmonary gas exchange in ischemia-reperfusion syndrome during temporary abdominal aortic occlusion in dogs. We studied 20 adult mongrel dogs weighing 12 to $23 \mathrm{~kg}$ divided into two groups: ischemia-reperfusion group (IRG, $\mathrm{N}=10$ ) and IRG submitted to saline infusion for the maintenance of mean pulmonary arterial wedge pressure between 10 and $20 \mathrm{mmHg}$ (IRG-SS, N = 10). All animals were anesthetized and maintained on spontaneous ventilation. After obtaining baseline measurements, occlusion of the supraceliac aorta was performed by the inflation of a Fogarty catheter. After 60 min of ischemia, the balloon was deflated and the animals were observed for another $60 \mathrm{~min}$ of reperfusion. The measurements were made at 10 and $45 \mathrm{~min}$ of ischemia, and 5, 30, and $60 \mathrm{~min}$ of reperfusion. Pulmonary gas exchange was impaired in the IRG-SS group as demonstrated by the increase of the alveolar-arterial oxygen difference $(21 \pm 14$ in IRG-SS vs $11 \pm 8$ in IRG after 60 min of reperfusion, $\mathrm{P}=0.004$ in IRG-SS in relation to baseline values) and the decrease of oxygen partial pressure in arterial blood $(58 \pm 15$ in IRG-SS vs $76 \pm 15$ in IRG after 60 min of reperfusion, $\mathrm{P}=0.001$ in IRG-SS in relation to baseline values), which was correlated with the highest degree of pulmonary edema in morphometric analysis $(0.16 \pm$ 0.06 in IRG-SS vs $0.09 \pm 0.04$ in IRG, $\mathrm{P}=0.03$ between groups). There was also a smaller ventilatory compensation of metabolic acidosis after the reperfusion. We conclude that infusion of normal saline worsened the gas exchange induced by pulmonary reperfusion injury in this experimental model.
\end{abstract}

\section{Introduction}

Surgical procedures requiring aortic occlusion have been associated with ischemiareperfusion lesions with homeostatic distur-
Key words

- Reperfusion lesion

- Fluid resuscitation

- Pulmonary gas exchange

- Lung edema 
After aortic declamping, severe hypotension with decreased cardiac output is a wellknown occurrence secondary to the precipitous reduction in vascular resistance, sequestration of blood volume in the distal capillary beds, and the negative inotropic effect of acidosis and myocardial depressant factors. The potential for hypovolemia may be worsened by intravascular fluid loss caused by capillary damage with reperfusion (4-7).

The amount of resulting hypovolemia during declamping can be attenuated by volume expansion. Fluid administration followed by adequate monitoring based on the physiology of cardiac function promotes good myocardial performance during surgical stress and in the postoperative period. It improves cardiac output and maintains systemic blood pressure, which is important for adequate coronary blood flow, thereby protecting the heart especially in patients with coronary occlusive disease (4-12).

Maintenance of pulmonary artery wedge pressure between 10 and $18 \mathrm{mmHg}$ during this procedure could prevent a decline in cardiac output and hypotension after aortic declamping (5-7,13-15). However, few studies have evaluated the impact of fluid infusion on pulmonary gas exchange. Furthermore, among the possible complications, the pulmonary ones have high incidence and mortality rate, which is mostly a consequence of pulmonary edema caused by ischemia and reperfusion of the aorta (16-22).

In view of the importance of the study of ischemia-reperfusion damage and of its potential in determining systemic alterations even in distant organs such as the lung, we conducted the present experiment. Our objective was to assess the effects of saline infusion for the maintenance of mean pulmonary artery wedge pressure between 10 and $20 \mathrm{mmHg}$ during aortic ischemia-reperfusion on dogs, especially in the shock phase after aortic declamping, on pulmonary gas exchange.

\section{Material and Methods}

Male adult mongrel dogs weighing 12 to $23 \mathrm{~kg}(\mathrm{~N}=20)$ were anesthetized intravenously with sodium thionembutal (Sodium Thiopental ${ }^{\circledR}$ CEME, Ministério da Saúde, Brasília, DF, Brazil - Brazil's Health Department) with an initial dose of $20 \mathrm{mg} / \mathrm{kg}$, followed by $5 \mathrm{mg} / \mathrm{kg}$ as needed to maintain anesthesia during the procedure. After induction of anesthesia, the dogs underwent endotracheal intubation with an 8-mm cannula and were allowed to breathe room air without mechanical ventilation throughout the experiment.

The left femoral artery was dissected and catheterized with an 8 French Fogarty occlusor, and the balloon was positioned in the descending thoracic aorta adjacent to the diaphragm at the level of the 10th thoracic vertebra for later occlusion. Aortic occlusion was therefore performed above the celiac trunk. Physical examination, laparotomy, and thoracotomy confirmed the correct position of the balloon at the end of the procedure in all dogs.

An 8 French polyethylene catheter was introduced through the right femoral artery, and its distal end was located in the distal abdominal aorta for monitoring mean abdominal aortic artery pressure distal to the occlusion. The mean systemic arterial pressure above the level of aortic occlusion was also monitored through the right carotid artery with an 8 French polyethylene catheter.

A triple-lumen model 7 French thermodilution pulmonary artery catheter was inserted through the right internal jugular vein and its progression was controlled by visualization of the pressure curves on an SDM2000 monitor (Dixtal Tecnologia, Manaus, AM, Brazil). The distal tip of the catheter was placed in the pulmonary artery. The proximal and distal portions of the pulmonary artery catheter were connected to a Statham P23 pressure transducer (Statham, Oxnard, CA, USA), permitting the determination of pressure 
curves of the right atrium, pulmonary artery, and pulmonary arterial wedge. The last hemodynamic variable was estimated through the pulmonary artery occlusion pressure, obtained with the inflation of the balloon at the distal end of the catheter. Cardiac output was determined by the thermodilution technique (23) with the debitometer of an SDM 2000 monitor (Dixtal Tecnologia).

The dogs were randomly assigned to two groups: ischemia-reperfusion (IRG, $\mathrm{N}=10$ ) and ischemia-reperfusion with saline infusion (IRG-SS, $\mathrm{N}=10$ ). In both groups, the criteria for the beginning of the experiment were arterial blood $\mathrm{pH} \geq 7.25$, arterial blood oxygen partial pressure $\geq 70 \mathrm{mmHg}$, mean pulmonary arterial wedge pressure $\geq 5 \mathrm{mmHg}$, and mean systemic arterial pressure $\geq 90 \mathrm{mmHg}$.

In the IRG, we first obtained baseline hemodynamic, metabolic and respiratory measurements (T0), and then performed aortic occlusion by inflating the Fogarty occlusor with saline until mean systemic arterial pressure below the occlusion reached values between 10 and $20 \mathrm{mmHg}$ and mercury column oscillation was not observed. After 60 min of aortic occlusion, the balloon was deflated and reperfusion was started. The animals were observed for another $60 \mathrm{~min}$ and then were sacrificed by venous administration of $50 \mathrm{mEq}$ potassium chloride. Open thoracotomy was then performed and two fragments of the left cardiac lung lobe were removed for histopathologic and morphometric analysis. Hemodynamic, metabolic and respiratory measurements were repeated at $10 \mathrm{~min}$ of ischemia (T10-I), $45 \mathrm{~min}$ of ischemia (T45-I), 5 min of reperfusion (T5$\mathrm{R}), 30 \mathrm{~min}$ of reperfusion (T30-R), and 60 min of reperfusion (T60-R). In the IRG-SS, the dogs underwent the same procedures and the same monitoring. The difference from the IRG group was the administration of saline solution in order to maintain mean pulmonary arterial wedge pressure between 10 and $20 \mathrm{mmHg}$ throughout the experiment.
For the collection of expired gas, the endotracheal cannula was attached to a Douglas bag through a two-way valve (Hans Rudolph Inc., Kansas City, MO, USA). After mixing, a gas sample was analyzed with a gas analyzer (ABL 330, Radiometer, Copenhagen, Denmark).

The pulmonary parameters studied were: respiratory rate, expiratory minute volume $\left(\dot{\mathrm{V}}_{\mathrm{E}}\right)$, partial pressure of oxygen in arterial blood $\left(\mathrm{PaO}_{2}\right)$, hemoglobin oxygen saturation in arterial blood $\left(\mathrm{SaO}_{2}\right)$, partial pressure of carbonic gas in arterial blood $\left(\mathrm{PaCO}_{2}\right)$, partial pressure of oxygen in alveolar gas $\left(\mathrm{P}_{\mathrm{A}} \mathrm{O}_{2}^{-}\right)$, alveolar-arterial oxygen gradient $\left(\mathrm{P}(\mathrm{A}-\mathrm{a}) \mathrm{O}_{2}\right)$, alveolar dead space fraction $\left(\mathrm{V}_{\mathrm{D}} /\right.$ $\mathrm{V}_{\mathrm{T}}$ ), respiratory quotient, and partial pressure of oxygen in venous blood $\left(\mathrm{PvO}_{2}\right)$. The hemodynamic parameters studied were: mean systemic arterial pressure, mean pulmonary arterial wedge pressure, and cardiac index. The metabolic parameters studied were: arterial $\mathrm{pH}$, arterial bicarbonate $\left(\mathrm{HCO}_{3}{ }^{-}\right)$, and lactate.

The $V_{D} / V_{T}$ ratio was calculated by Enghoff modification of the Bohr equation (24): $\mathrm{V}_{\mathrm{D}} / \mathrm{V}_{\mathrm{T}}=\left(\mathrm{PaCO}_{2}-\mathrm{P}_{\mathrm{E}}^{-} \mathrm{CO}_{2}\right) \div \mathrm{PaCO}_{2}$, where $\mathrm{P}_{\mathrm{E}}^{-} \mathrm{CO}_{2}$ is the partial pressure of carbon dioxide in expired gas.

Morphometric analysis was carried out by the point-counting technique. For this purpose we used an optical microscope equipped with an integrating eyepiece containing 100 points and 50 lines. We studied the alveolar edema index. At a magnification of 400, we analyzed 10 randomly selected fields of the proximal section and 10 fields of the distal section. The correlation between the number of points of the eyepiece falling on alveolar edema and the number of points falling on the whole alveolar lumen was determined (25).

Differences between groups regarding hemodynamic, metabolic and pulmonary variables were studied by multivariate analysis of profiles with repeated measurements analyzing variations in relation to baseline 
values and the parallelism and coincidence of parameters between groups (26). Differences in alveolar edema index between the two groups were analyzed with the Student $t$-test. The level of significance was set at 5\% $(\mathrm{P}<0.05)$ in all analyses.

The study was approved by the Ethics Committee for Animal Research of Escola Paulista de Medicina (Paulista Medical School), Universidade Federal de São Paulo (Federal University of São Paulo), São Paulo, SP, Brazil.

\section{Results}

Significant hemodynamic parameters are shown in Table 1. For the IRG-SS group, the values of mean pulmonary arterial wedge pressure during the whole procedure were within the range stipulated for this experimental model, i.e., 10 to $20 \mathrm{mmHg}$. Furthermore, saline infusion was suitable for minimizing hemodynamic changes, avoiding hypotension ( $\mathrm{P}=0.04$ for parallelism between groups) and a decrease in the cardiac index $(\mathrm{P}=0.01$ for parallelism between groups) after aortic declamping.

Significant respiratory parameters are shown in Figure 1, Table 2, and Table 3. After aortic declamping, a decrease in base- line values $(\mathrm{P}=0.001$ in $\mathrm{T} 45-\mathrm{R}$ and $\mathrm{P}=$ 0.001 in $\mathrm{T} 60-\mathrm{R}$ ) occurred for $\mathrm{PaO}_{2}$ in IRGSS but not in IRG. The same pattern was observed regarding $\mathrm{SaO}_{2}(\mathrm{P}=0.047$ for parallelism between groups). $\mathrm{P}(\mathrm{A}-\mathrm{a}) \mathrm{O}_{2}$ was increased in IRG-SS after aortic declamping $(\mathrm{P}=0.014$ in T30- $\mathrm{R}$ and $\mathrm{P}=0.004$ in T60$R)$, but not in IRG. Although $V_{E}$ increased in both groups, it was greater in IRG $(\mathrm{P}=0.039$ for coincidence between groups). $\mathrm{PaCO}_{2}$ decreased in IRG but not in IRG-SS (P = 0.007 for coincidence between groups). $\mathrm{V}_{\mathrm{D}} /$ $\mathrm{V}_{\mathrm{T}}$ was increased in both groups after aortic occlusion. However, the increase was greater in IRG-SS ( $\mathrm{P}=0.024$ for coincidence between groups). No difference was observed between groups regarding respiratory rate $(\mathrm{P}=0.510$ for parallelism and $\mathrm{P}=0.963$ for coincidence between groups) or respiratory quotient $(\mathrm{P}=0.561$ for parallelism and $\mathrm{P}=$ 1.591 for coincidence between groups).

Significant metabolic parameters and $\mathrm{PvO}_{2}$ are shown in Table 4. Acidosis was greater in IRG-SS ( $\mathrm{P}=0.046$ for coincidence between the groups). $\mathrm{HCO}_{3}{ }^{-}$always showed lower values in IRG-SS than in IRG $(\mathrm{P}=0.003$ for parallelism between the groups). Lactate was similar in both groups. No difference was observed between groups regarding $\mathrm{P}_{\bar{v}} \mathrm{O}_{2}$.

Table 1. Effect of ischemia-reperfusion with saline infusion on mean pulmonary arterial wedge pressure (MPAWP), mean systemic arterial pressure (MAP) and cardiac index (Cl) in the ischemia-reperfusion group (IRG) and the group submitted to ischemia-reperfusion with saline infusion (IRG-SS).

\begin{tabular}{|c|c|c|c|c|c|c|}
\hline & \multicolumn{2}{|c|}{ MPAWP (mmHg) } & \multicolumn{2}{|c|}{ MAP $(\mathrm{mmHg})$} & \multicolumn{2}{|c|}{$\mathrm{Cl}\left(\mathrm{L} \min ^{-1}\left(\mathrm{~m}^{2}\right)^{-1}\right)$} \\
\hline & $\mathrm{IRG}$ & IRG-SS & $\mathrm{IRG}$ & IRG-SS & $\mathrm{IRG}$ & IRG-SS \\
\hline T0 & $7 \pm 2$ & $7 \pm 3$ & $133 \pm 12$ & $128 \pm 17$ & $5.70 \pm 1.17$ & $5.79 \pm 2.72$ \\
\hline T10-I & $13 \pm 8$ & $19 \pm 5^{*}$ & $174 \pm 24^{*}$ & $176 \pm 24^{*}$ & $4.96 \pm 1.83$ & $5.73 \pm 1.69$ \\
\hline T45-I & $11 \pm 4$ & $18 \pm 5^{*}$ & $175 \pm 20^{*}$ & $161 \pm 28^{*}$ & $4.26 \pm 1.31^{*}$ & $4.07 \pm 1.12^{*}$ \\
\hline T5-R & $3 \pm 2$ & $13 \pm 5^{*}$ & $97 \pm 27^{*}$ & $120 \pm 23$ & $2.72 \pm 0.69^{*}$ & $5.25 \pm 0.92$ \\
\hline T30-R & $2 \pm 1^{*}$ & $12 \pm 2^{*}$ & $101 \pm 14^{*}$ & $124 \pm 20$ & $2.65 \pm 0.81^{*}$ & $5.47 \pm 1.54$ \\
\hline T60-R & $2 \pm 1^{*}$ & $10 \pm 2^{*}$ & $94 \pm 14^{*}$ & $117 \pm 18$ & $2.47 \pm 0.63^{*}$ & $5.28 \pm 1.42$ \\
\hline
\end{tabular}

Data are reported as means \pm SD. Measurements were made at 0 (T0), 10 (T10-I) and 45 (T45-I) min of ischemia (I) and at 5 (T5-R), 30 (T30-R) and 60 (T60-R) min of reperfusion (R).

There was a difference in parallelism between IRG and IRG-SS for each parameter measured $(P<0.05$, repeated-measures analysis of variance). ${ }^{*} \mathrm{P}<0.05$ compared to baseline values (repeated-measures analysis of variance). 
Histopathologic and morphometric analysis demonstrated pulmonary edema and congestion, mainly interstitial, in both groups. The alveolar edema index was more intense in IRG-SS $(0.16 \pm 0.06$ vs $0.09 \pm 0.04 ; \mathrm{P}=$ $0.030)$.

\section{Discussion}

As demonstrated in several studies, saline infusion with maintenance of mean pulmonary arterial wedge pressure is suitable for minimizing hemodynamic changes after release of the aortic clamps, mainly avoid- ing hypotension and a decrease in cardiac index (5-7,13-15). However, in the present study this procedure caused worsening of gas exchange as shown by an increase in $\mathrm{P}(\mathrm{A}-\mathrm{a}) \mathrm{O}_{2}$ after aortic declamping in IRG$\mathrm{SS}$, determining a progressive decrease in $\mathrm{PaO}_{2} . \mathrm{SaO}_{2}$ also had decreased progressively due to hypoxemia and to the reduction of the affinity of hemoglobin for oxygen due to the greater acidosis in IRG-SS.

Morphometric analysis demonstrated more intense pulmonary edema in IRG-SS, determining a decrease in gas exchange in individuals of this group.

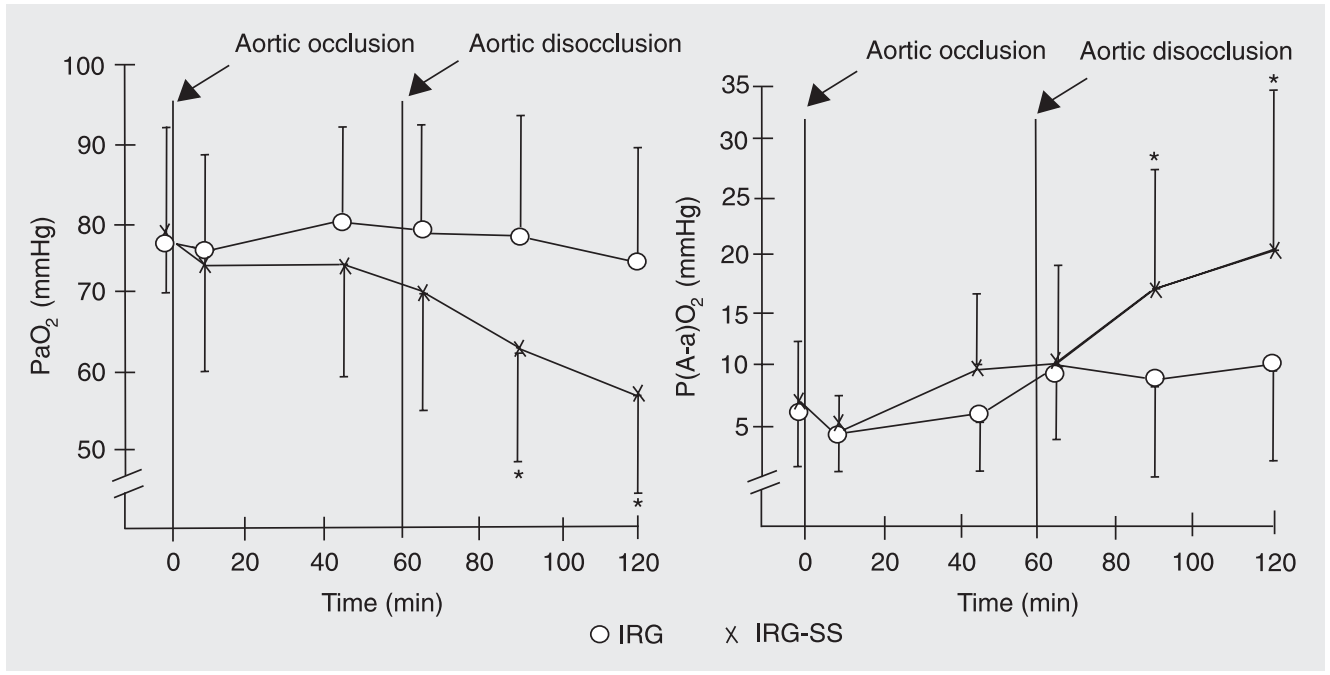

Figure 1. Changes in arterial blood partial oxygen pressure $\left(\mathrm{PaO}_{2}\right)$ and alveolar-arterial oxygen gradient $\left(P(A-a) O_{2}\right)$ in the ischemia-reperfusion group (IRG, circles) and the group submitted to ischemia-reperfusion with saline infusion (IRG-SS, crosses). ${ }^{*} \mathrm{P}<0.05$ vs IRG (repeatedmeasures analysis of variance).

Table 2. Effect of ischemia-reperfusion with saline infusion on respiratory rate $(f)$, expiratory minute volume $\left(V_{E}\right)$, alveolar-arterial oxygen gradient $\left(P(A-a) O_{2}\right)$, and alveolar dead space fraction $\left(V_{D} / V_{T}\right)$ in the ischemiareperfusion group (IRG) and the group submitted to ischemia-reperfusion with saline infusion (IRG-SS).

\begin{tabular}{|c|c|c|c|c|c|c|c|c|}
\hline & \multicolumn{2}{|c|}{$f(\mathrm{bpm})$} & \multicolumn{2}{|c|}{$V_{E}(L / k g)$} & \multicolumn{2}{|c|}{$\mathrm{P}(\mathrm{A}-\mathrm{a}) \mathrm{O}_{2}(\mathrm{mmHg})$} & \multicolumn{2}{|c|}{$\mathrm{V}_{\mathrm{D}} / \mathrm{V}_{\mathrm{T}}$} \\
\hline & $\mathrm{IRG}$ & IRG-SS & IRG & IRG-SS & IRG & IRG-SS & IRG & IRG-SS \\
\hline T0 & $25 \pm 12$ & $26 \pm 16$ & $0.30 \pm 0.12$ & $0.34 \pm 0.12$ & $6 \pm 5$ & $7 \pm 5$ & $0.52 \pm 0.17$ & $0.55 \pm 0.10$ \\
\hline T10-I & $59 \pm 18^{*}$ & $53 \pm 27^{*}$ & $0.37 \pm 0.11^{*}$ & $0.45 \pm 0.11^{*}$ & $4 \pm 3$ & $4 \pm 3$ & $0.62 \pm 0.11^{*}$ & $0.73 \pm 0.11^{*}$ \\
\hline T45-I & $47 \pm 16^{*}$ & $45 \pm 18$ & $0.41 \pm 0.10^{*}$ & $0.41 \pm 0.11^{*}$ & $6 \pm 5$ & $10 \pm 7$ & $0.58 \pm 0.13$ & $0.71 \pm 0.11^{*}$ \\
\hline T5-R & $56 \pm 10^{*}$ & $63 \pm 22^{*}$ & $0.57 \pm 0.23^{*}$ & $0.63 \pm 0.19^{*}$ & $10 \pm 6$ & $11 \pm 8$ & $0.63 \pm 0.10^{*}$ & $0.73 \pm 0.06^{*}$ \\
\hline T30-R & $57 \pm 14^{*}$ & $60 \pm 28^{*}$ & $0.56 \pm 0.23^{*}$ & $0.47 \pm 0.14$ & $9 \pm 8$ & $17 \pm 11$ & $0.59 \pm 0.13$ & $0.73 \pm 0.08^{*}$ \\
\hline T60-R & $48 \pm 9^{*}$ & $56 \pm 26$ & $0.51 \pm 0.20^{*}$ & $0.48 \pm 0.15^{*}$ & $11 \pm 8$ & $21 \pm 14^{*}$ & $0.65 \pm 0.12$ & $0.72 \pm 0.09^{*}$ \\
\hline
\end{tabular}

Data are reported as means \pm SD. Measurements were made at 0 (T0), 10 (T10-I) and 45 (T45-I) min of ischemia (I) and at 5 (T5-R), 30 (T30-R) and 60 (T60-R) min of reperfusion (R).

There was a difference in coincidence between IRG and IRG-SS for $V_{E}$ and $V_{D} / V_{T}(P<0.05$, repeatedmeasures analysis of variance). ${ }^{*} \mathrm{P}<0.05$ compared to baseline values (repeated-measures analysis of variance). 
Moreover, mean pulmonary arterial wedge pressure always remained below 18 $\mathrm{mmHg}$ during the reperfusion period in IRGSS and the cardiac index also increased, demonstrating the non-cardiogenic etiology of the pulmonary edema.

Other investigators have provoked pulmonary edema to a greater or lesser extent in different models of ischemia-reperfusion injury. Anner et al. (27) detected areas of alveolar edema in dogs submitted to ischemia for aortic cross-clamping for $4 \mathrm{~h}$ followed by $4 \mathrm{~h}$ of reperfusion, Klausner et al. (28), using a sheep model of ischemic-reperfusion injury for $2 \mathrm{~h}$ of bilateral hind limb tourniquet ischemia, followed by $4 \mathrm{~h}$ of reperfusion, detected pulmonary edema by histopathological analysis, and Nielsen et al.

Table 3. Effect of ischemia-reperfusion with saline infusion on partial oxygen pressure in arterial blood $\left(\mathrm{PaO}_{2}\right)$, partial carbonic gas pressure in arterial blood $\left(\mathrm{PaCO}_{2}\right)$, hemoglobin oxygen saturation in arterial blood $\left(\mathrm{SaO}_{2}\right)$, and respiratory quotient in the ischemia-reperfusion group (IRG) and the group submitted to ischemia-reperfusion with saline infusion (IRG-SS).

\begin{tabular}{|c|c|c|c|c|c|c|c|c|}
\hline & \multicolumn{2}{|c|}{$\mathrm{PaO}_{2}(\mathrm{mmHg})$} & \multicolumn{2}{|c|}{$\mathrm{PaCO}_{2}(\mathrm{mmHg})$} & \multicolumn{2}{|c|}{$\mathrm{SaO}_{2}(\%)$} & \multicolumn{2}{|c|}{ Respiratory quotient } \\
\hline & $\mathrm{IRG}$ & IRG-SS & IRG & IRG-SS & $\mathrm{IRG}$ & IRG-SS & IRG & IRG-SS \\
\hline T0 & $79 \pm 13$ & $80 \pm 8$ & $41 \pm 8$ & $40 \pm 6$ & $95 \pm 1$ & $94 \pm 1$ & $0.7 \pm 0.3$ & $0.8 \pm 0.1$ \\
\hline T10-I & $77 \pm 13$ & $74 \pm 14$ & $44 \pm 5$ & $46 \pm 4^{*}$ & $89 \pm 7$ & $89 \pm 7^{*}$ & $0.7 \pm 0.3$ & $0.8 \pm 0.1$ \\
\hline T45-I & $81 \pm 11$ & $74 \pm 14$ & $34 \pm 6$ * & $42 \pm 4$ & $94 \pm 3$ & $90 \pm 6^{*}$ & $0.6 \pm 0.2$ & $0.8 \pm 0.1$ \\
\hline T5-R & $80 \pm 14$ & $70 \pm 15$ & $34 \pm 6^{*}$ & $43 \pm 7$ & $90 \pm 5$ & $80 \pm 19^{*}$ & $0.8 \pm 0.2$ & $0.8 \pm 0.1$ \\
\hline T30-R & $79 \pm 15$ & $63 \pm 15^{\star}$ & $33 \pm 6$ & $44 \pm 13$ & $93 \pm 2$ & $86 \pm 9^{*}$ & $0.6 \pm 0.2$ & $0.7 \pm 0.1$ \\
\hline T60-R & $76 \pm 15$ & $58 \pm 15^{*}$ & $33 \pm 7$ & $44 \pm 13$ & $93 \pm 3$ & $76 \pm 17^{*}$ & $0.6 \pm 0.2$ & $0.6 \pm 0.1$ \\
\hline
\end{tabular}

Data are reported as means \pm SD. Measurements were made at 0 (T0), 10 (T10-I) and 45 (T45-I) min of ischemia (I) and at 5 (T5-R), 30 (T30-R) and 60 (T60-R) min of reperfusion (R).

There was a difference in parallelism between IRG and IRG-SS for $\mathrm{SaO}_{2}(P<0.05$, repeated-measures analysis of variance). There was a difference in coincidence between IRG and IRG-SS for $\mathrm{PaCO}_{2}(\mathrm{P}<0.05$, repeated-measures analysis of variance). ${ }^{*} \mathrm{P}<0.05$ compared to baseline values (repeated-measures analysis of variance).

Table 4. Effect of ischemia-reperfusion with saline infusion on arterial blood $\mathrm{pH}(\mathrm{pHa})$, arterial blood bicarbonate $\left(\mathrm{HCO}_{3}{ }^{-}\right)$, partial oxygen pressure in venous blood $\left(\mathrm{PvO}_{2}\right)$, and lactate in the ischemia-reperfusion group (IRG) and the group submitted to ischemia-reperfusion with saline infusion (IRG-SS).

\begin{tabular}{|c|c|c|c|c|c|c|c|c|}
\hline & \multicolumn{2}{|c|}{$\mathrm{pHa}$} & \multicolumn{2}{|c|}{$\mathrm{HCO}_{3}^{-}(\mathrm{mEq} / \mathrm{L})$} & \multicolumn{2}{|c|}{$\mathrm{PvO}_{2}(\mathrm{mmHg})$} & \multicolumn{2}{|c|}{ Lactate $(\mathrm{mg} / 100 \mathrm{~mL})$} \\
\hline & IRG & IRG-SS & IRG & IRG-SS & IRG & IRG-SS & IRG & IRG-SS \\
\hline T0 & $7.28 \pm 0.08$ & $7.31 \pm 0.07$ & $18.5 \pm 2.9$ & $19.1 \pm 3.4$ & $58 \pm 15$ & $47 \pm 6$ & $13 \pm 4$ & $12 \pm 6$ \\
\hline T10-I & $7.22 \pm 0.11$ & $7.13 \pm 0.07^{*}$ & $16.9 \pm 2.7^{*}$ & $14.5 \pm 2.0^{*}$ & $54 \pm 4$ & $56 \pm 5$ & - & - \\
\hline T45-I & $7.20 \pm 0.10^{*}$ & $7.08 \pm 0.08^{*}$ & $12.8 \pm 2.5^{*}$ & $12.1 \pm 1.7^{*}$ & $62 \pm 4^{*}$ & $59 \pm 4^{*}$ & $35 \pm 10^{*}$ & $36 \pm 18^{*}$ \\
\hline T5-R & $7.11 \pm 0.11^{*}$ & $7.01 \pm 0.10^{*}$ & $10.6 \pm 2.8^{*}$ & $10.3 \pm 1.6^{*}$ & $48 \pm 3$ & $50 \pm 7$ & $46 \pm 16^{*}$ & $48 \pm 21^{*}$ \\
\hline T30-R & $7.15 \pm 0.13^{*}$ & $7.03 \pm 0.14^{*}$ & $11.4 \pm 2.7^{*}$ & $10.5 \pm 1.7^{*}$ & $51 \pm 13$ & $46 \pm 6$ & - & - \\
\hline T60-R & $7.17 \pm 0.14$ & $7.03 \pm 0.16^{*}$ & $11.8 \pm 3.0^{*}$ & $10.7 \pm 2.0^{*}$ & $52 \pm 14$ & $39 \pm 10$ & $28 \pm 15^{*}$ & $22 \pm 13^{*}$ \\
\hline
\end{tabular}

Data are reported as means \pm SD. Measurements were made at 0 (T0), 10 (T10-I) and 45 (T45-I) min of ischemia (I) and at 5 (T5-R), 30 (T30 -R) and 60 (T60-R) min of reperfusion (R).

There was a difference in parallelism between IRG and IRG-SS for $\mathrm{HCO}_{3}(P<0.05$, repeated-measures analysis of variance). There was a difference in coincidence between IRG and IRG-SS for $\mathrm{pHa}(\mathrm{P}<0.05$, repeated-measures analysis of variance). ${ }^{*} \mathrm{P}<0.05$ compared to baseline values (repeated-measures analysis of variance). 
(29) also found pulmonary edema detected by the increase of the relation between the dry and humid weights of the lung in an experimental study with aortic cross-clamping with Fogarty occlusor for $40 \mathrm{~min}$ followed by $2 \mathrm{~h}$ of reperfusion. Furthermore, increased micro-vascular permeability, edema and neutrophil infiltration of the lungs were reported in several studies on ischemicreperfusion injury $(18,19,27,30)$.

Although the mechanism of the ischemareperfusion lung injury is still unclear, a number of putative etiological factors, including oxidative stress (reactive oxygen species, ROS) (27,31-33), tumor necrosis factor (34), up-regulation of molecules on the surface of the cell membrane (P-selectin and E-selectin) (35), and neutrophil adherence receptors (CD18), have been proposed (36). Among the mediators, ROS play a prominent role in ischemic-reperfusion injury. ROS such as superoxide anion $\left(\cdot \mathrm{O}_{2}\right)$, hydrogen peroxide, hypochlorous acid, nitric oxide-derived peroxynitrite, and hydroxyl radical $(\cdot \mathrm{OH})$ are produced within minutes of reperfusion and continue to be generated for hours after the restoration of blood flow to ischemic tissue, and damage cells directly by altering membrane proteins and phospholipids. Because these membrane constituents play crucial roles as receptors, enzymes, and ion channels, ROS can lead to fatal metabolic and structural derangements $(22,32)$. The role for ROS as a source of significant reperfusion damage is further supported by studies showing that the potent antioxidant $\mathrm{N}$-acetylcysteine administered before reperfusion ameliorate the ischemicreperfusion injury (33).

The more intense pulmonary edema in IRG-SS agreed with findings of increased pulmonary microvascular permeability after ischemia and reperfusion of the aorta. Paterson et al. (37) and Grindlinger et al. (8) detected pulmonary edema without evidence of left ventricular failure in patients undergoing abdominal aortic aneurysm surgery.
In these studies, a mild increase in postoperative pulmonary arterial wedge pressure from 9 to $12 \mathrm{mmHg}$ related to the large fluid infusion tended to promote a movement of fluid into the alveoli secondary to increased permeability.

Abnormalities of pulmonary blood flow and injury to the microcirculation are characteristic features of acute lung injury. Classically, right-to-left intrapulmonary shunt leading to arterial hypoxemia has been considered the primary physiological abnormality in the early acute lung injury that we observed here by a worsening of $\mathrm{PaO}_{2}$ and $\mathrm{P}(\mathrm{A}-\mathrm{a}) \mathrm{O}_{2}$ in IRG-SS. However, the $\mathrm{V}_{\mathrm{D}} / \mathrm{V}_{\mathrm{T}}$ ratio is markedly elevated very early in the course of non-cardiogenic pulmonary edema, an event that we also observed in IRG-SS $(38,39)$. Possible mechanisms include injury of pulmonary capillaries by thrombotic and inflammatory mechanisms, obstruction of pulmonary blood flow in the extra-alveolar pulmonary circulation, and areas with a high ventilation-perfusion ratio as a result of the compromised pulmonary blood flow to lung regions that remain well ventilated. Regardless of the mechanism, it is clear that both altered excretion of carbon dioxide and impaired oxygenation are characteristic physiological abnormalities of the early phase of acute lung injury. Interestingly, an elevated $\mathrm{V}_{\mathrm{D}} / \mathrm{V}_{\mathrm{T}}$ has been shown to be a predictor of mortality in non-cardiogenic pulmonary edema (39).

Furthermore, $V_{\mathrm{E}}$ was reduced in the IRG$\mathrm{SS}$, and became even worse with the increase of $\mathrm{V}_{\mathrm{D}} / \mathrm{V}_{\mathrm{T}}$. Consequently, $\mathrm{PaCO}_{2}$ did not decrease in the IRG-SS during reperfusion. In fact, respiratory acidosis was associated with metabolic acidosis in the IRG-SS, as shown by the levels of $\mathrm{PaCO}_{2}$. The reduced $\mathrm{V}_{\mathrm{E}}$ and the lack of respiratory compensation of metabolic acidosis reflect acute respiratory failure with fatigue of the respiratory muscles (40).

We conclude that, in the present experimental model, saline infusion for the main- 
tenance of blood volume resulted in the worsening of pulmonary reperfusion injury and lung gas exchange, as observed by the increase of $\mathrm{P}(\mathrm{A}-\mathrm{a}) \mathrm{O}_{2}$, the decrease of $\mathrm{PaO}_{2}$, impairment of the ventilatory compensation of metabolic acidosis after reperfusion, and increased alveolar edema index.

\section{References}

1. Cornu-Labat G, Serra M, Smith A, McGregor WE, Kasirajan K, Hirko $\mathrm{MK}$, et al. Systemic consequences of oxidative stress following aortic surgery correlate with the degree of antioxidant defenses. Ann Vasc Surg 2000; 14: 31-36.

2. Rigberg DA, McGory ML, Zingmond DS, Maggard MA, Agustin M, Lawrence PF, et al. Thirty-day mortality statistics underestimate the risk of repair of thoracoabdominal aortic aneurysms: a statewide experience. J Vasc Surg 2006; 43: 217-222.

3. Gloviczki P. Surgical repair of thoracoabdominal aneurysms: patient selection, techniques and results. Cardiovasc Surg 2002; 10: 434441.

4. Perry MO. The hemodynamics of temporary abdominal aortic occlusion. Ann Surg 1968; 168: 193-200.

5. Falk JL, Rackow EC, Blumenberg R, Gelfand M, Fein IA. Hemodynamic and metabolic effects of abdominal aortic crossclamping. Am J Surg 1981; 142: 174-177.

6. Bush HL Jr, LoGerfo FW, Weisel RD, Mannick JA, Hechtman HB. Assessment of myocardial performance and optimal volume loading during elective abdominal aortic aneurysm resection. Arch Surg 1977; 112: 1301-1305.

7. Lunn JK, Dannemiller FJ, Stanley TH. Cardiovascular responses to clamping of the aorta during epidural and general anesthesia. Anesth Analg 1979; 58: 372-376.

8. Grindlinger GA, Vegas AM, Manny J, Bush HL, Mannick JA, Hechtman HB. Volume loading and vasodilators in abdominal aortic aneurysmectomy. Am J Surg 1980; 139: 480-486.

9. Whittemore AD, Clowes AW, Hechtman HB, Mannick JA. Aortic aneurysm repair. Reduced operative mortality associated with maintenance of optimal cardiac performance. Ann Surg 1980; 192: 414421.

10. Silverstein PR, Caldera DL, Cullen DJ, Davison JK, Darling RC, Emerson CW. Avoiding the hemodynamic consequences of aortic cross-clamping and unclamping. Anesthesiology 1979; 50: 462466.

11. Skillman JJ, Patel RC, Klick JM. Cardiac performance testing by volume loading and lower-extremity compression. Arch Surg 1982; 117: 1009-1011.

12. Rosenthal MH. Intraoperative fluid management - what and how much? Chest 1999; 115: 106S-112S.

13. Huval WV, Lelcuk S, Allen PD, Mannick JA, Shepro D, Hechtman $\mathrm{HB}$. Determinants of cardiovascular stability during abdominal aortic aneurysmectomy (AAA). Ann Surg 1984; 199: 216-222.

14. Reiz S, Peter T, Rais O. Hemodynamic and cardiometabolic effects of infrarenal aortic and common iliac artery declamping in man - an approach to optimal volume loading. Acta Anaesthesiol Scand 1979; 23: $579-586$.

15. Amorim FF, Pinheiro Bd Bdo V, Romaldini H. Metabolic and hemodynamic effects of saline infusion to maintain volemia on temporary abdominal aortic occlusion. Arq Bras Cardiol 2002; 79: 395-404.

16. West CA, Noel AA, Bower TC, Cherry KJ Jr, Gloviczki P, Sullivan
TM, et al. Factors affecting outcomes of open surgical repair of pararenal aortic aneurysms: a 10-year experience. $J$ Vasc Surg 2006; 43: 921-927.

17. Adembri C, Kastamoniti E, Bertolozzi I, Vanni S, Dorigo W, Coppo $\mathrm{M}$, et al. Pulmonary injury follows systemic inflammatory reaction in infrarenal aortic surgery. Crit Care Med 2004; 32: 1170-1177.

18. van Griensven M, Stalp M, Seekamp A. Ischemia-reperfusion directly increases pulmonary endothelial permeability in vitro. Shock 1999; 11: 259-263.

19. Iglesias JL, LaNoue JL, Rogers TE, Inman L, Turnage RH. Physiologic basis of pulmonary edema during intestinal reperfusion. $J$ Surg Res 1998; 80: 156-163.

20. Back MR, Bandyk M, Bradner M, Cuthbertson D, Johnson BL, Shames ML, et al. Critical analysis of outcome determinants affecting repair of intact aneurysms involving the visceral aorta. $J$ Vasc Surg 2005; 19: 648-656.

21. Welborn MB, Oldenburg HS, Hess PJ, Huber TS, Martin TD, Rauwerda JA, et al. The relationship between visceral ischemia, proinflammatory cytokines, and organ injury in patients undergoing thoracoabdominal aortic aneurysm repair. Crit Care Med 2000; 28: 3191-3197.

22. Pinheiro BV, Horta CM, Baldia BG, Schiavon LL, Gollner AM, Oliveira JC. Pulmonary reperfusion injury by aortic occlusion: experimental model in rats. J Pneumologia 2000; 26: 163-168.

23. Khalil HH, Richardson TQ, Guyton AC. Measurement of cardiac output by thermal-dilution and direct Fick methods in dogs. J Appl Physiol 1966; 21: 1131-1135.

24. West JB, Wagner PD. Ventilation, blood flow, and gas exchange. In: Murray JF, Nadel JA (Editors), Textbook of respiratory medicine. 3rd edn. Philadelphia: W.B. Saunders; 2000. p 55-89.

25. Weibel ER. Principles and methods for the morphometric study of the lung and other organs. Lab Invest 1963; 12: 131-155.

26. Singer JM, Andrade DF. Analysis of longitudinal data. In: Sen PK, Rao CR (Editors), Handbook of Statistics. 18th edn. Amsterdam: Bio-Environmental and Public Health Statistics; 2000.

27. Anner H, Kaufman RP Jr, Kobzik L, Valeri CR, Shepro D, Hechtman HB. Pulmonary hypertension and leukosequestration after lower torso ischemia. Ann Surg 1987; 206: 642-648.

28. Klausner JM, Anner H, Paterson IS, Kobzik L, Valeri CR, Shepro D, et al. Lower torso ischemia-induced lung injury is leukocyte dependent. Ann Surg 1988; 208: 761-767.

29. Nielsen VG, Tan S, Weinbroum A, McCammon AT, Samuelson PN, Gelman S, et al. Lung injury after hepatoenteric ischemia-reperfusion: role of xanthine oxidase. Am J Respir Crit Care Med 1996; 154: 1364-1369.

30. Harkin DW, Barros D'Sa AA, McCallion K, Hoper M, Campbell FC. Ischemic preconditioning before lower limb ischemia-reperfusion protects against acute lung injury. J Vasc Surg 2002; 35: 12641273.

31. Carden DL, Granger DN. Pathophysiology of ischaemia-reperfusion 
injury. J Pathol 2000; 190: 255-266.

32. de Perrot M, Liu M, Waddell TK, Keshavjee S. Ischemia-reperfusion-induced lung injury. Am J Respir Crit Care Med 2003; 167: 490511.

33. Holanda MA, Pinheiro BV, Araújo FG, Percário S, Romaldini H. Nacetylcysteine effect in dogs submitted to ischemia-reperfusion (I-R) syndrome by aortic occlusion. Am J Respir Crit Care Med 1996; 153: 812 (Abstract).

34. Adam DJ, Lee AJ, Ruckley CV, Bradbury AW, Ross JA. Elevated levels of soluble tumor necrosis factor receptors are associated with increased mortality rates in patients who undergo operation for ruptured abdominal aortic aneurysm. J Vasc Surg 2000; 31: 514519.

35. Carden DL, Young JA, Granger DN. Pulmonary microvascular injury after intestinal ischemia-reperfusion: role of P-selectin. J Appl Physiol 1993; 75: 2529-2534.
36. Welbourn R, Goldman G, Kobzik L, Paterson IS, Valeri CR, Shepro $D$, et al. Role of neutrophil adherence receptors (CD 18) in lung permeability following lower torso ischemia. Circ Res 1992; 71: 8286.

37. Paterson IS, Klausner JM, Pugatch R, Allen P, Mannick JA, Shepro $D$, et al. Noncardiogenic pulmonary edema after abdominal aortic aneurysm surgery. Ann Surg 1989; 209: 231-236.

38. Gattinoni L, Bombino M, Pelosi P, Lissoni A, Pesenti A, Fumagalli R, et al. Lung structure and function in different stages of severe adult respiratory distress syndrome. JAMA 1994; 271: 1772-1779.

39. Nuckton TJ, Alonso JA, Kallet RH, Daniel BM, Pittet JF, Eisner MD, et al. Pulmonary dead-space fraction as a risk factor for death in the acute respiratory distress syndrome. N Engl J Med 2002; 346: 12811286.

40. Roussos C, Koutsoukou A. Respiratory failure. Eur Respir J Suppl 2003; 47: 3s-14s. 